\title{
Allergologie den Allergologen!
}

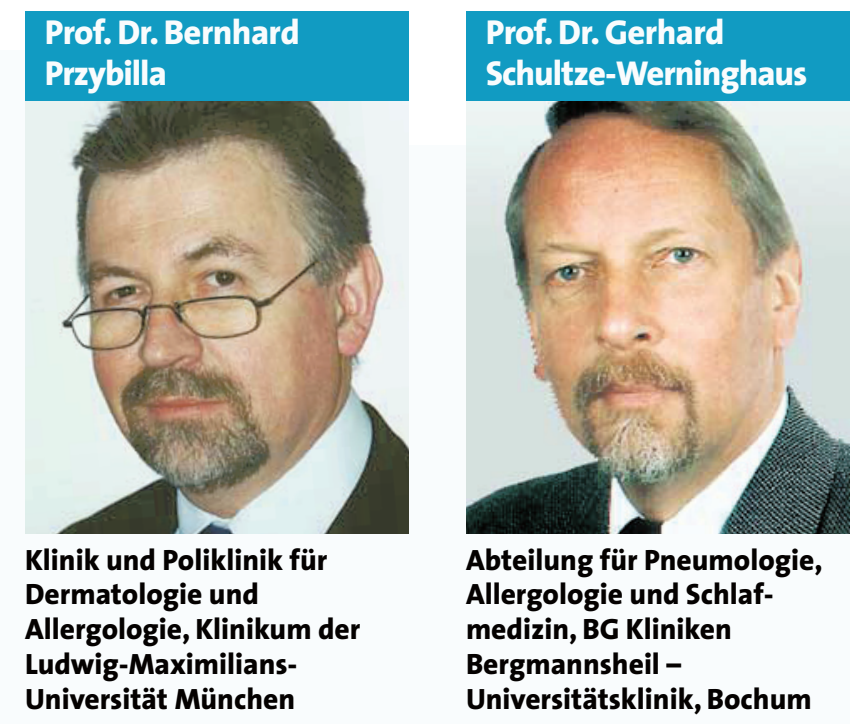

den ja von DGAI und ÄDA seit einigen Jahren äußerst erfolgreich betrieben! Der Allergiekranke wird so auf die spezialisierten Inhalte und Möglichkeiten der Medizin aufmerksam - wer sein Brot beim Bäcker kauft, wird auch seine Allergie vom Allergologen behandeln lassen!

Spezialistenwissen finden Sie auch wieder in dieser Ausgabe von Allergo Journal. Die Charakterisierung von Allergendosis-Wirkungs-Beziehungen ist ein höchst erstrebenswertes, angesichts der multifaktoriellen Bedingtheit allergischer Erkrankungen aber schwer erreichbares Ziel (Seiten 452 und 456). Berichte über „ungewöhnliche“ Allergene faszinieren zunächst durch

ihre Exotik; dabei „Wer sein Brot beim kann eine solche Bäckerkauft, wird auch allergische Erkran- seine Allergie vom kung bei berufli- Allergologen cher Exposition für behandeln lassen " den Betroffenen schwerwiegende, lebensverändernde Konsequenzen haben - durch geeignete Primärprävention wäre diese ungünstige Entwicklung möglicherweise zu verhindern (Seite 448). Wie ein in einer bestimmten Situation lebenswichtiger Arzneistoff trotz Allergie vertragen wurde, lesen Sie auf Seite 443.

Wir wünschen Ihnen viel Spaß beim Lesen, besinnliche Weihnachtstage und ein friedvolles Neues Jahr!

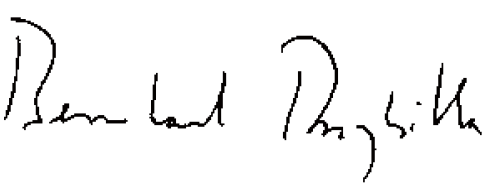

Prof. Dr. B. Przybilla

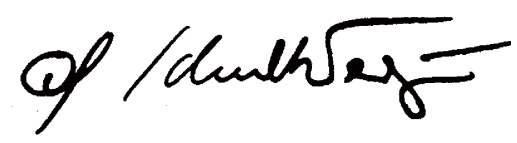

Prof. Dr. G. Schultze-Werninghaus 